\title{
ESTUDOS REEP
}

\section{A relação família-escola: implicações no desempenho escolar dos alunos dos anos iniciais do ensino fundamental*}

\author{
Adriana Varani \\ Daiana Cristina Silva
}

\begin{abstract}
Resumo
Objetiva compreender a relação família-escola e suas possíveis implicações no desempenho escolar dos alunos dos anos iniciais do ensino fundamental, por meio de um estudo de caso em uma escola pública. Foram construídos os seguintes indicadores de análise: alternativas da escola para aproximar os pais da vida escolar dos filhos, tipo de participação das famílias e implicações da relação família-escola no desempenho dos alunos. Como resultados, a análise dos dados confirma a tese de que, embora a família exerça um papel fundamental no desenvolvimento das crianças, ela não pode ser considerada como a única responsável pelo seu sucesso ou pelo seu fracasso escolar. O estudo também evidencia e reflete sobre as diversas possibilidades da participação da família no cotidiano escolar.
\end{abstract}

Palavras-chave: família-escola; desempenho escolar; fracasso escolar.

* Texto publicado originalmente nas Actas do X Congresso Internacional Galego-Português de Psicopedagogia, realizado na Universidade do Minho, em Braga, Portugal, em 2009. 


\section{Abstract \\ The family-school relationship: implications for the performance of students during primary school years}

The article aims at understanding the family-school relationship and its possible implications on the performance of pupils in the first years of elementary school, by means of a case study in a public school. The following indicators were constructed for the analysis: the alternative ways school has to bring parents into their childrens' school life, the types of family participation, and implications of family-school relationship for student performance. As a result, the analysis of the data confirms the view that, although the family exerts a fundamental role in children development, it cannot be regarded as solely responsible for their success or failure at school. The study also reveals and reflects on the various possibilities of family participation in school daily life.

Keywords: family-school relationship; schooling performance; schooling failure.

\section{Introdução}

Nos últimos anos, muito tem se falado e debatido sobre as causas do sucesso e do fracasso escolar. Pesquisadores, como Polônia e Dessen (2005) e Paro (2007), apontam que tradicionalmente a família tem estado por trás do discurso sobre o sucesso escolar e tem sido culpada pelo fracasso escolar de seus filhos. Segundo Polônia e Dessen (2005), muitas vezes a família é vista como a impulsionadora da produtividade na escola, e o distanciamento da vida estudantil de seus filhos como um provocador em potencial do desinteresse e da desvalorização da educação. Essa questão foi verificada ao longo dos períodos de realização dos estágios do curso de Pedagogia, em especial, quando numa escola municipal de ensino fundamental de $1^{\mathrm{a}}$ a $4^{\mathrm{a}}$ série, $^{1}$ foram presenciadas algumas cenas, nas quais professores afirmavam que uma das dificuldades enfrentadas no ambiente escolar era decorrente da participação da família no processo de ensino-aprendizagem dos alunos.

Tal questão se transformou em tema de trabalho de pesquisa na graduação, tendo como objetivos buscar compreender que tipo de relação há entre família e escola e suas possíveis implicações no desempenho escolar dos alunos dos anos iniciais do ensino fundamental e contribuir para com a desmistificação de concepções (dos profissionais e não

\footnotetext{
1 Apesar de ser algo presenciado por grande parte dos alunos do curso de Pedagogia, focamos uma certa escola e dedicamos uma atenção especial em razão do projeto de trabalho de final de curso para aprofundamento daquilo que vinha sendo presenciado, mas não registrado de forma mais sistemática.
} 
profissionais da educação) de que é a família ou a escola, ou ambas, as únicas instituições culpadas pelo sucesso ou pelo fracasso escolar das crianças. Este estudo vem se juntar a vários outros que se dedicam a mostrar que são vários os fatores - econômicos, políticos, sociais e culturais - que podem influenciar no desempenho escolar dos alunos. A pesquisa apresentada aqui também faz apontamentos acerca da importância da integração entre família e escola no desenvolvimento da criança e do tipo de participação que se espera que os pais tenham na instituição de ensino, destacando a participação democrática - na tomada de decisões escolares - como a ideal. Com esta pesquisa, buscamos chamar a atenção dos leitores e levantar possíveis reflexões a respeito da real necessidade de revermos as formas como vem se dando a participação das famílias nas escolas.

\section{Dos caminhos do trabalho}

Para obter respostas aos objetivos propostos, foi realizada uma pesquisa de caráter empírico e bibliográfico. Empírico porque foi embasada na relação família-escola da instituição campo da pesquisa, onde foram feitos levantamentos de dados referentes às implicações que repercutem no desempenho escolar dos alunos a partir dessa relação, das alternativas utilizadas pela escola para aproximar os pais da trajetória estudantil de seus filhos e do processo pedagógico e de como se dá a participação da família na vida escolar dos alunos. A pesquisa foi desenvolvida numa escola pública municipal de ensino fundamental, localizada em uma cidade do interior do Estado de São Paulo, e os dados foram coletados durante os meses de maio a outubro do ano de 2008.

Bibliográfico porque, para desenvolver este trabalho, foram revisados títulos de livros, artigos científicos e revistas especializadas em estudos institucionais de estabelecimentos de ensino fundamental, direcionados à prática pedagógica e à educação formal e informal no âmbito familiar. A pesquisa foi fundamentada na abordagem qualitativa de tipo históricoestrutural, dialética. A escolha por esse tipo de abordagem decorre do fato de esta partir "[...] da descrição que intenta captar não só a aparência do fenômeno, como também sua essência" (Triviños, 1995, p. 129). A opção por técnicas qualitativas de análise ocorre por ela ser "[...] um enfoque que permite fazer um enlace constante e permanente entre a teoria e a prática, durante o próprio desenrolar do trabalho" (Moysés, 1994, p. 12).

Para a construção dos dados de pesquisa, foram utilizados como instrumentos: entrevista, documentos, conversa informal, observação e diário de campo.

O estudo de caso visou à superação de algumas ideias e conceitos já enraizados em nossa sociedade atual, no que diz respeito à relação famíliaescola; desse estudo, foi realizada uma análise descritiva dos dados coletados. Para uma melhor organização da pesquisa, a análise foi disposta pelos seguintes indicadores analítico-descritivos: as alternativas utilizadas pela 
instituição de ensino para aproximar os pais da trajetória estudantil de seus filhos; como se dá a participação da família na vida escolar dos alunos; e as implicações que repercutem no desempenho escolar dos alunos, a partir da relação família-escola.

\section{Sobre os estudos realizados}

Por meio de estudos bibliográficos, constatou-se que as sociedades que deram origem à constituição da família nuclear (composta de pais, mães e filhos) sofreram inúmeras transformações no decorrer do tempo. Ariés (1978, p. 273) aponta que no período da Idade Média não havia intimidade familiar, a vida no passado, até o século 17, era vivida em público, "[...] as pessoas viviam misturadas umas com as outras, senhores e criados, crianças e adultos, em casas permanentemente abertas às indiscrições dos visitantes [...]." O autor esclarece, ainda, que as crianças, aproximadamente, aos sete anos de idade, eram mergulhadas na sociedade e ingressavam na grande comunidade dos homens, sua educação era garantida pela aprendizagem junto aos adultos e ministrada por uma outra família; "não havia lugar para a escola nessa transmissão através da aprendizagem direta de uma geração a outra" (p. 229), e o ensino era voltado para a experiência prática.

De acordo com Ariés (1978, p. 225), com o passar do tempo "[...] a família transformou-se profundamente na medida em que modificou suas relações internas com as crianças" e começou a estabelecer um laço de intimidade com os filhos, a se preocupar com sua educação e a cultivar um sentimento de afeto para com eles. Conforme o autor, a partir da segunda metade do século 17, período em que marca o início da Idade Moderna, a aprendizagem tradicional é substituída pela escola.

Nas últimas décadas, na Idade Contemporânea, houve grandes alterações na separação de papéis entre o homem e a mulher, e a clássica divisão de tarefas pai/provedor e mãe/rainha do lar foi modificada.

Venosa (2005) aponta que a composição familiar é transformada drasticamente com o processo de industrialização, com a passagem da economia agrária à economia industrial. A família, neste momento, deixa de ser uma unidade de produção, na qual todos os membros trabalhavam sob a autoridade de um chefe. Os homens passam a dirigir-se para as fábricas e as mulheres lançam-se para o mercado de trabalho.

A saída das mulheres de suas casas para o mercado de trabalho, de acordo com Duarte (2000), foi uma das molas propulsoras nas zonas urbanas para a criação de instituições de educação infantil específicas, e, segundo a autora, com a criação desses estabelecimentos, as famílias deixam de ser o único núcleo protetor das crianças.

Venosa destaca que a transformação do papel da mulher no século 20 acarretou sensíveis efeitos no meio familiar. Ele afirma que, atualmente, as mulheres alcançaram os mesmos direitos dos maridos na maioria das legislações, e com isso a convivência entre pais e filhos foi transfigurada. 
Os filhos passaram a viver mais tempo na escola e em atividades fora do lar, distanciando-se da vida familiar. Este autor afirma que,

[..]atualmente, a escola e outras instituições de educação, esportes e recreação preenchem atividades dos filhos que originalmente eram responsabilidade dos pais. Os ofícios não mais são transmitidos de pai para filho dentro dos lares e das corporações de ofício. A educação cabe ao Estado ou a instituições privadas por ele supervisionadas (Venosa, 2005, p. 22).

As transformações ocorridas em nossa sociedade levaram a uma divisão de responsabilidades. Hoje, em nossa sociedade contemporânea, a família não é mais a única responsável pelo desenvolvimento da educação escolar das crianças. De acordo com o art. $4^{\circ}$ do Estatuto da Criança e do Adolescente, Lei no 8.069, de 13 de julho de 1990:

É dever da família, da comunidade, da sociedade em geral e do Poder Público assegurar, com absoluta prioridade, a efetivação dos direitos referentes à vida, à saúde, à alimentação, à educação, ao esporte, ao lazer, à profissionalização, à cultura, à dignidade, ao respeito, à liberdade e à convivência familiar e comunitária (Brasil, 1990).

Segundo Malavazi (2000, p. 258), há uma troca de papéis entre família e escola, em que a instituição de ensino está cada vez mais se preocupando com normas de condutas das crianças e a família se ocupando do ensino de seus filhos, mas "[...] algumas atribuições são específicas da família que tem o direito de reivindicá-las para si, enquanto outras cabem a escola que, pela sua natureza, poderá ocupar-se melhor delas".

Essas transformações sociais ocorridas na família e na escola camuflaram as atribuições específicas de cada uma delas. Conforme Assis (1994, p. 130), é papel da escola "[...] promover o desenvolvimento do indivíduo, tornando-o capaz de enfrentar múltiplas situações [...]". Ele aponta que a escola é uma das instâncias mais importantes da sociedade e destaca que sua função é ensinar, não se limitando "[...] à simples aquisição de conteúdos, uma vez que o conteúdo, por si só, não desenvolve as habilidades mentais necessárias à formação de um raciocínio flexível e criativo [...]" (p. 129-130). A escola, segundo Paro (2007), é uma agência que propicia a apropriação do saber historicamente produzido.

Libâneo, Oliveira e Toschi (2007, p. 304) afirmam que o objetivo primordial da escola é o ensino e a aprendizagem dos discentes e pontuam que "é a escola como um todo que deve responsabilizar-se pela aprendizagem dos alunos [...]" À instituição de ensino cabe também o reconhecimento da importância da colaboração dos pais na história e no projeto escolar, o auxílio às famílias no exercício de seu papel na educação, no desenvolvimento e no sucesso profissional de seus filhos e, concomitantemente, na transformação da sociedade (Polônia, Dessen, 2005).

A escola, segundo Polônia e Dessen, é um espaço privilegiado para o desenvolvimento de ideias, crenças e valores, por isso, ela deve ir além da apreensão de conteúdos, buscando a formação de cidadãos inseridos 
na sociedade, críticos e agentes de transformação. Ela "[...] tem por principal tarefa na nossa sociedade a democratização dos conhecimentos, garantindo uma cultura de base para todas as crianças e jovens" (Libâneo, 1996, p. 127).

Já a família tem como um dos principais papéis a socialização da criança, ou seja, a inclusão desta no mundo cultural mediante o ensino da língua materna, dos símbolos e das regras de convivência em sociedade (Polônia e Dessen, 2005). De acordo com Gabriela Portugal (1990, apud Duarte, 2000), a função primária da família é educar e criar as crianças.

Malavazi (2000) também aponta que competem à família o auxílio na organização escolar e a transmissão do equilíbrio emocional e afetivo para a formação humana das crianças. Para Kaloustian (1998, p.11-12),

[...] a família é o espaço indispensável para a garantia da sobrevivência de desenvolvimento e da proteção integral dos filhos e demais membros, independentemente do arranjo familiar ou da forma como se vêm estruturando. É a família que propicia os aportes afetivos e, sobretudo, materiais necessários ao desenvolvimento e bem-estar dos seus componentes. Ela desempenha um papel decisivo na educação formal e informal, é em seu espaço que são absorvidos o valor ético e humanitário, e onde se aprofundam os laços de solidariedade.

O Estatuto da Criança e do Adolescente traz em seu art. 22 que "aos pais incumbe o dever de sustento, guarda e educação dos filhos menores, cabendo-lhes ainda, no interesse destes, a obrigação de cumprir as determinações judiciais" e em seu art. 55 afirma que "os pais ou responsáveis têm obrigação de matricular seus filhos ou pupilos na rede regular de ensino" (Brasil, 1990).

A educação é um dever da família e da escola. Ambas devem interagir para garantir os direitos da criança nas questões referentes ao ensino, dando-lhes suporte e apoio para o pleno desenvolvimento da aprendizagem.

Dos estudos realizados, constatou-se também que nas escolas a integração com os pais tem se estabelecido sobre diversas formas. Ela tem se dado pela ajuda pecuniária dos pais, contribuição financeira por meio da Associação de Pais e Mestres (APM), participação em eventos com fins lucrativos (festa junina, entre outros), ajuda com a tarefa de casa e também mediante prestação de serviço a escola. Frequentemente, os pais têm estado presentes na instituição de ensino para realizar pequenos reparos, serviços de limpeza, preparação da merenda, organização ou cumprimento de tarefas ligadas a festas, excursões, entre outras (Paro, 2007, 2008).

Entretanto, Paro (2001, p. 67) destaca que a participação dos pais e da comunidade no processo pedagógico "[...] não pode cair no equívoco de delegar aos pais e à comunidade aquilo que compete ao Estado, por meio da escola, realizar." Não se trata de os pais prestarem uma ajuda unilateral à instituição de ensino nem de a escola repassar parte de seu trabalho aos pais; não basta permitir formalmente que as famílias participem da administração da escola e também "[...] não se pode exigir que 
eles participem do que não têm condições de dar conta e que é obrigação da escola fazê-lo [...]" (Paro, 2008, p. 52).

Para este autor, é necessária a extensão da função educativa (não doutrinária) da escola para as famílias responsáveis pelos alunos. A instituição de ensino necessita da adesão de seus usuários aos propósitos educativos a que ela deve visar, e essa adesão deve redundar em ações efetivas que contribuam para o bom desempenho dos alunos. A participação da família na escola precisa estar "[...] ligada à tomada de decisões e não como mera forma de prestação de serviços ou de contribuição financeira por parte da população" (Paro, 2007, p. 10). Participando das tomadas de decisões da escola, os pais,

[...] além de terem melhores condições de influir nas tomadas de decisão a respeito das ações e objetivos da escola, eles estarão investindo na melhoria da qualidade da educação de seus filhos, bem como na melhoria de sua própria qualidade de vida, na medida em que esses adultos estarão mais capazes, intelectualmente, de usufruir melhor de bens culturais a que têm direito e que antes não estavam a seu alcance. (Paro, 2001, p. 68).

Outro importante resultado obtido com a pesquisa diz respeito à desmistificação das causas do fracasso escolar.

Patto (1999, p. 41) traz reflexões muito importantes acerca de como o fracasso escolar foi percebido no processo histórico da sociedade capitalista. Ele aponta que as desigualdades sociais, inerentes à nova ordem social, passaram a ser justificadas pelas desigualdades raciais, pessoais ou culturais, sem colocar em xeque a tese da existência de igualdade de oportunidades. Inicialmente, houve "[...] a crença de que a divisão social em classes superiores e inferiores teria como critério o talento individual [...]." No final do século 18 e no século 19, as crianças que não acompanhavam seus colegas na aprendizagem escolar passaram a ser intituladas como anormais escolares e seu fracasso passou a ser procurado e justificado por meio de alguma anormalidade orgânica.

A partir da segunda metade do século 19, houve outras explicações para justificar a desigualdade existente entre as pessoas no novo mundo - capitalista. Patto destaca que o racismo, afirmação da existência de raças inferiores ou indivíduos constitucionalmente inferiores, foi uma das ideologias usadas para fundamentar a conquista de outros povos e as diferenças de classes.

Já no século 20, o fracasso escolar começa a ser justificado pela afirmação da existência de culturas inferiores ou diferentes, de grupos familiares patológicos e de ambientes sociais atrasados que produzem crianças desajustadas e problemáticas, e as causas dos desajustes infantis passam, nesse momento, a serem buscadas no ambiente sociofamiliar (Patto, 1999).

A autora destaca que, no início dos anos 70, a teoria da carência cultural em sua primeira formulação afirmou "[...] que a pobreza ambiental nas classes baixas produz deficiências no desenvolvimento psicológico 
infantil [...]" (Patto, 1999, p. 124); e essas deficiências são na teoria da carência cultural as causas das dificuldades de aprendizagem e de adaptação escolar. A autora cita, ainda, que essa teoria defendia que "[...] a causa principal do fracasso encontrava-se no aluno, cabendo à escola uma parcela de responsabilidade por não se adequar a este aluno de baixa renda", e condenava "[...] a criança pobre a um ensino não adequado e, portanto, ao fracasso escolar num sistema obviamente não-igualitário" (Patto, p. 145-158).

Charlot (2000), ao refletir sobre o fracasso escolar, aponta que esta questão nos remete para muitos debates: sobre o aprendizado, a eficácia dos docentes, o serviço público, a igualdade das "chances", os recursos que o País deve investir em seu sistema de ensino, os modos de vida e o trabalho na sociedade de amanhã, entre outros. Para este autor, "o 'fracasso escolar' não existe; o que existe são alunos fracassados, situações de fracasso, histórias escolares que terminam mal" (Charlot, 2000, p. 16). Ele afirma, também, que as situações de fracasso e as histórias escolares que terminam mal devem ser analisadas, "[...] e não algum objeto misterioso, ou algum vírus resistente, chamado 'fracasso escolar'".

Segundo Charlot (2000), para que o fracasso escolar seja analisado, deve-se levar em consideração o fato de que ele "tem alguma coisa a ver" com a posição social da família, no entanto, não se pode reduzir essa posição a um lugar em uma nomenclatura socioprofissional, nem a família a uma posição. O fato de o fracasso escolar ter alguma relação com a desigualdade social não permite, em absoluto, afirmar que a origem social do indivíduo é a causa do fracasso escolar. O autor defende a ideia de que o "fracasso escolar" é um fator que deve ser analisado individualmente, em sua singularidade. No entanto, ele não é um produto isolado, é contextualizado dentro de uma perspectiva histórica de cada sujeito.

Autores como Paro (2007), Abramowicz (1997), Nunes (1996 apud Coelho, 1997), Coelho (1997), Esteban (2003), Franco (2005) e Malavazi (2000) também trazem reflexões acerca de algumas situações que podem favorecer a existência de alunos fracassados na escola. Essas situações estão relacionadas a: má aparelhagem da escola, métodos inadequados de ensino, má formação dos professores, elevado número de alunos por classe na escola pública brasileira, sobrecarga da escola em suas funções, construções escolares inacabadas e mal conservadas, equipamentos em precária condição de uso, baixos salários dos docentes, formação e atualização continuada inexistente ou inadequada, funcionamento escolar em regime de vários turnos, pouco interesse governamental em promover parcerias com universidades públicas para respaldar o trabalho educativo dos docentes do ensino fundamental, negação da legitimidade de conhecimentos e formas de vida formulados à margem dos limites socialmente definidos como válidos e utilização de modelos inadequados, parciais e fragmentados de avaliação.

É importante que se tenha claro que a estrutura da família é também resultado de uma estrutura social, e a relação família-escola também é resultado de outras relações da sociedade. É relevante recordar aqui a 
argumentação de Charlot (2000) em que destaca o fracasso escolar como um fato que deve ser contextualizado dentro da perspectiva histórica do sujeito analisado, o que não significa individualizar o problema e culpabilizar o aluno.

O fato de a relação família-escola ser apenas uma faceta no processo do fracasso escolar não isenta a família de exercer seu importante papel, o de sustentar, guardar e educar os filhos menores, o que para Aquino (1998) também é o de moralização da criança.

Paro (2001, p. 58), quanto ao papel da família para com a educação, enfatiza a importância da adesão dos pais aos propósitos educativos da escola e destaca "[...] que essa adesão precisa redundar em ações efetivas que contribuam para o bom desempenho do estudante". Conforme este autor, para o bom desempenho dos alunos há um caminho longo a percorrer no interior da própria escola, "[...] em termos da adequação de seus objetivos e de seu aparelhamento material, humano e metodológico", e enfatiza que não se pode estar alheio a isto, destacando a necessidade

[...] de reconhecer algo a que a teoria educacional tem prestado pouca atenção. Por pequena que seja, em comparação com tudo o que há por fazer na escola, a contribuição que os pais podem dar para o processo pedagógico escolar precisa ser levada em conta para evitar o risco de se ignorar algo que é imprescindível para o bom desempenho dos alunos (Paro, 2001, p. 72).

\section{Da viagem pelos dados coletados}

Do estudo de caso, constatou-se que a instituição campo de pesquisa promoveu os seguintes eventos visando à participação/presença dos pais: bazar da pechincha, festa do sorvete, comemoração do dia das mães, festa junina, quatro reuniões de pais e mestres, duas reuniões do Conselho de Escola (CE) e duas reuniões da APM. De acordo com o observado e com o registro em diário de campo, verificou-se que em eventos, como bazar da pechincha, festa do sorvete e comemoração do dia das mães, a participação dos pais na escola é mínima. A instituição de ensino, por meio desses eventos, abre espaço para que os pais apenas contribuam financeiramente e se façam presentes de forma passiva, sem ação, ou seja, eles não são convidados a colaborar com a elaboração do evento, a dar sugestões, a participar e a se envolver com a escola.

Já as reuniões de pais e mestres, observadas em uma sala de $2^{a}$ série da instituição campo, diferenciam-se dos eventos discutidos acima à medida que oferecem aos pais uma maior abertura para a participação e o envolvimento com a escola, pois são os únicos eventos que permitem essa manifestação. Por meio dos dados coletados em sala de aula de uma $2^{a}$ série, foi possível verificar que nessas reuniões os pais encontram espaço para se fazer presente, participar e se pronunciar, visto que a professora, durante o período de reunião, está sempre atenta aos olhares deles e constantemente lhes pergunta: 
"Vocês têm alguma dúvida, algum questionamento a fazer?" (Diário de campo, p. 24).

"Existe algo que vocês queiram colocar?" (Diário de campo, p. 43).

Mediante as observações realizadas, foi possível notar a preocupação por parte desta professora em ouvir a opinião dos pais a respeito dos assuntos tratados nas reuniões. Entretanto, os pais, na maioria das vezes, mostram-se bastante tímidos na hora de participar, expor sua opinião no coletivo, preferem conversar com a professora individualmente e tratar de assuntos que dizem respeito exclusivamente a seus filhos.

Outras alternativas oferecidas pela escola, como meio de promover a participação dos pais/comunidade no que se refere aos assuntos escolares, são as reuniões do CE e as da APM, também chamadas de coletivos. Segundo Paro (2008, p. 113), esses coletivos têm o propósito prioritário de "[...] fazer da participação dos pais um objeto de preocupação e um fim da própria escola, de modo a aproximar a família das questões pedagógicas e a tornar a unidade escolar integrada ao seu meio [...]". Porém, ao buscar informações por meio da diretora a respeito do CE e da APM, ela disse que no ano letivo de 2008 só foram feitas duas reuniões do CE e duas da APM; quanto ao Conselho, foi realizada uma reunião para eleger seus membros representantes e outra individual, com cada participante, para prestar conta do recebimento da verba do Programa Dinheiro Direto na Escola (PDDE) e coletar as assinaturas dos representantes. É importante destacar que a última reunião do CE foi apenas para prestar conta do recebimento da verba do PDDE aos membros representantes e não para decidir coletivamente onde ela seria investida. Em relação à APM, foi também realizada uma reunião para eleger os membros representantes e outra individual, com cada participante, apenas para informar os gastos e os lucros obtidos com o evento da festa junina.

A partir do relato da diretora da instituição campo, verifica-se que os coletivos têm assumido um caráter formalista e uma gestão burocratizada. Nesses coletivos, os membros representantes não tomam decisões nem organizam ações, eles apenas assinam documentos e são informados a respeito de recebimentos de verbas, de entrada e saída de dinheiro do caixa da escola e de ações realizadas com esses recursos.

Foi também constatado que os gestores da instituição campo de pesquisa reconhecem a importância da parceria entre família e escola e estão sempre trazendo esse assunto à tona. No entanto, embora a escola admita a relevância da participação da família na vida escolar dos alunos, ela ainda não consegue promover o envolvimento entre ambas. O projeto político-pedagógico (PPP) da instituição de ensino comprova esta afirmação e explana a importância da integração entre família/comunidade e escola; entretanto, foi elaborado pelos gestores e professores da instituição campo sem a colaboração dos pais e da comunidade.

De acordo com Paro (2008, p. 13), para que as famílias façam parte das tomadas de decisões, "não basta permitir formalmente que os pais de alunos participem da administração da escola, é preciso que haja 
condições propiciadoras dessa participação" e que a escola ofereça ocasiões de diálogo, convivência e inclusão na vida escolar e promova a extensão da função educativa para os pais e a participação destes nas decisões da instituição de ensino, pois só assim eles terão as condições necessárias para influir a respeito das ações e objetivos da escola e

[...] estarão investindo na melhoria da qualidade da educação de seus filhos bem como na melhoria de sua própria qualidade de vida, na medida em que esses adultos estarão mais capazes, intelectualmente, de usufruir melhor de bens culturais a que têm direito e que antes não estavam a seu alcance (Paro, 2001, p. 68).

Como podemos verificar, os envolvidos com a instituição de ensino (pais, alunos, professores, gestores, funcionários e comunidade escolar) só têm a ganhar com a integração e o relacionamento da família com a escola.

Por meio do estudo de caso, constatou-se também que, embora os pais dos alunos da $2^{\mathrm{a}}$ série da instituição campo de pesquisa procurem estar presentes nos eventos promovidos pela escola (Tabela 1), a participação deles se resume a contribuir financeiramente, a comparecer aos eventos - não sendo convidados a colaborar com sua organização -, a auxiliar os filhos nas tarefas de casa, além da grande preocupação em acompanhar seus filhos mediante as reuniões de pais e mestres.

A contribuição financeira dos pais para com a escola se dá pelo envio de dinheiro para a APM e para a fotocópia de atividades pedagógicas (não obrigatórias) e pela compra de roupas, sapatos (bazar da pechincha) e comida (nas festas juninas e do sorvete).

Já o auxílio com as tarefas de casa e o acompanhamento dos filhos nas reuniões de pais e mestres são os mais importantes meios de interação dos pais com a escola. Em relação às tarefas de casa, Libâneo (1991 apud Paula, 2000) destaca que, ao auxiliarem seus filhos, os pais tomam contato com o trabalho realizado na instituição de ensino.

As reuniões de pais e mestres também constituem meios pelos quais os pais tomam esse contato e são a forma mais expressiva de envolvimento deles com a escola. Embora, muitas vezes, mostrem-se tímidos quando estão na presença de outros pais, no diálogo individual com o professor, demonstram-se muito interessados no que diz respeito ao desenvolvimento escolar do filho.

É relevante ressaltar aqui que nem todos os pais participam da mesma forma, uns comunicam-se mais, outros menos. A professora da $2^{\mathrm{a}}$ série observada aponta que os pais não participam mais devido "a questão de tempo, disponibilidade e até mesmo a falta de conhecimento do papel que eles podem ocupar" (Diário de entrevista, p. 7). Segundo a professora, a não participação dos pais na escola acontece também porque não há uma boa comunicação da escola com a família. Ela diz:

Infelizmente eu acho que só um convitinho, um simples convitinho, não é suficiente pra trazer o pai pra escola. Eu acho que é preciso envolver os pais nos eventos, é preciso participar os pais. E não só os 


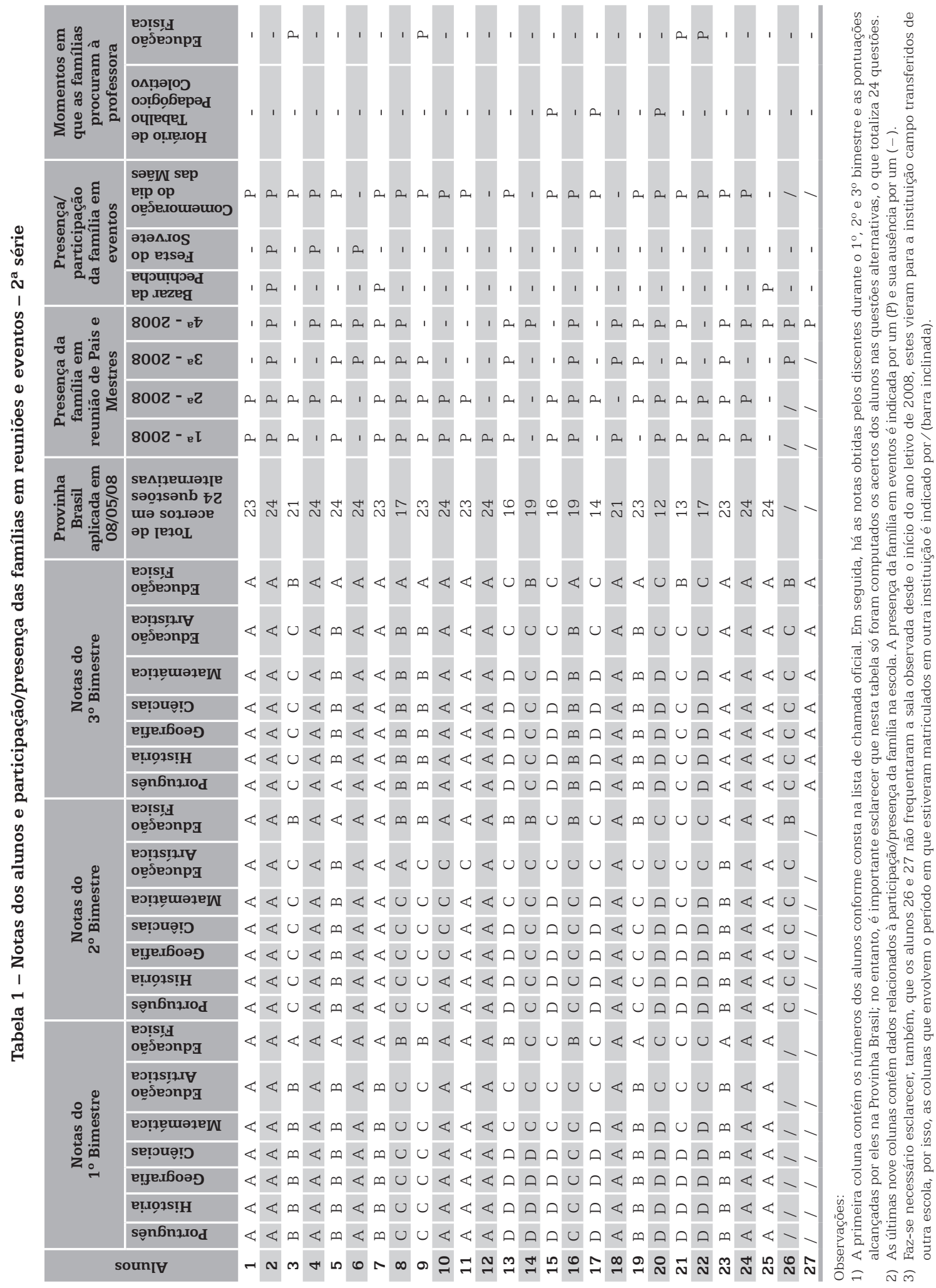


pais, é preciso envolver os alunos também no evento, é preciso fazer assembléia com os alunos, é preciso explicar parte de tudo que vai estar acontecendo na escola, é preciso envolver os alunos na confecção do que vai acontecer na escola. Eu acho que, toda festa, todo evento tem que ser proposto e participativo, e não simplesmente vai ter uma festa. Eu acho que isso não é suficiente pra que haja uma efetiva participação de todos na escola (Diário de entrevista, p. 2-3).

De acordo com o relato dessa professora, "[...] a escola tem que se preparar para receber esses pais" (Diário de Entrevista, p. 8). Mas como se preparar?

Paro (2008), em relação a uma participação democrática dos pais/ comunidade na escola, aponta que esta não se dá espontaneamente, ela é resultado de um processo histórico de construção coletiva. O autor destaca que há a necessidade de a escola prever mecanismos institucionais que não apenas viabilizem a participação dos pais, mas também incentivem práticas participativas dentro da escola. Paro (2007, p. 10) destaca, ainda, que a participação dos pais na escola deve sempre estar "[...] ligada à tomada de decisões e não como mera forma de prestação de serviços ou de contribuição financeira [...]". A presença dos pais na instituição de ensino deve ser entendida por todos como mecanismo de representação e participação política (Spósito, 2001).

Por fim, concernente às implicações que repercutem no desempenho escolar dos alunos a partir da relação família-escola, constatou-se com base na pesquisa realizada na $2^{\mathrm{a}}$ série que a participação/presença dos pais na instituição de ensino não determina o bom ou o mau desempenho escolar dos alunos. Exemplo disto são os casos dos discentes 12, 13, 15, 17, 20, 21, 22 e 25 (Tabela 1).

É interessante notar que outros aspectos também podem ser observados na Tabela 1:

a) Casos em que a presença/participação da família implicou o desempenho escolar dos alunos 1, 2, 4, 5, 6, 7, 8, 9, 10, 14, 16 e 23.

- Os estudantes 1, 2, 4, 5, 6, 7, 10 e 23 possuem um bom desempenho escolar e suas famílias têm uma presença expressiva na escola.

- Os alunos 8, 9 e 16 apresentaram progressos em seus desempenhos escolares ao longo dos bimestres e suas famílias têm uma presença expressiva na escola.

- O discente 14, no $1^{\circ}$ bimestre, não apresentou um bom desempenho escolar, mas progrediu a partir do $2^{\circ}$ bimestre. No entanto, sua família só esteve presente na escola em apenas uma reunião de pais e mestres.

b) Casos em que a presença/participação da família não implicou o desempenho escolar dos alunos (estudante 3):

- O aluno 3 apresentou uma queda em seu desempenho escolar a partir do $2^{\circ}$ bimestre, no entanto sua família esteve presente na escola em duas reuniões de pais e mestres e em um evento 
e procurou a professora para conversar no horário de educação física dos discentes.

Como se pode perceber, o bom ou o mau desempenho escolar dos estudantes não pode aqui ser justificado somente pela presença ou ausência da família na escola. Em entrevista realizada com a professora da $2^{a}$ série observada, ela pontua bem o caso explicitado na Tabela 1 , quando diz:

[...] a gente percebe que as crianças que tem um sucesso maior na escola, lógico que existe uma certa valorização por parte dos pais em relação a escola, mas por outro lado também, é... Não tem como a gente generalizar, existem crianças que não tem apoio familiar e tem sucesso na escola. Então, cada caso é um caso, não tem como a gente falar só porque a família valoriza então há sucesso. Não, a maioria dos casos sim, mas também há caso em que a família não dá apoio, não ajuda e que a criança tem sucesso. Então, é uma questão individual, de criança pra criança (Diário de entrevista, p. 1).

A família, de acordo com Polônia e Dessen (2005), exerce uma função muito importante no desenvolvimento e na aprendizagem humana. Ela é a primeira a incluir, por meio do ensino da língua materna, dos símbolos e das regras de convivência em grupo, as crianças no mundo cultural e é quem transmite para elas a educação geral e parte da formal, em colaboração com a escola. Entretanto, a família não pode assumir sozinha a culpa pelo sucesso ou pelo fracasso escolar dos alunos, como foi observado pelo trabalho de campo e pela análise da Tabela 1, construída a partir da relação família-escola.

\section{Alguns apontamentos finais}

Por meio dos resultados obtidos com a pesquisa, conclui-se que, embora a família seja fundamental no processo de desenvolvimento integral das crianças, ela não pode assumir sozinha a culpa pelo sucesso ou pelo fracasso escolar dos alunos, pois o bom ou o mau desempenho escolar não depende exclusivamente da participação/presença ou não da família na escola. Outros inúmeros fatores (sociais, políticos, econômicos e culturais) influem no desempenho, bem como no sucesso ou no fracasso escolar dos alunos, inclusive o tipo de participação requerido para a família.

Entre esses inúmeros fatores também estão a aparelhagem da escola, os métodos de ensino, a formação dos professores, o número de alunos por classe (Paro, 2007), as funções extracurriculares assumidas pela escola (Abramowicz, 1997), os baixos salários dos professores, a estrutura física e material, o regime de funcionamento escolar em vários turnos (Nunes, 1996 apud Coelho, 1997), os modelos de avaliação utilizados (Franco, 2005; Malavazi, 2000), entre outros.

Como foi averiguado, à família cabe o papel de cuidar e educar bem as crianças e à escola cabe cuidar da educação formal (sistemática) e 
promover o desenvolvimento físico, social, intelectual, emocional, moral e afetivo dos alunos. Conclui-se, também, que a integração de ambas as instituições (família-escola) é fundamental para com o desenvolvimento global das crianças e para com a melhoria da qualidade de vida dos pais dos alunos e também da escola.

\section{Referências bibliográficas}

ABRAMOWICZ, Anete. Quem são as crianças multirrepetentes? In: ABRAMOWICZ, Anete; MOLL, Jaqueline (Orgs.). Para além do fracasso escolar. 4. ed. Campinas, São Paulo: Papirus, 1997. Cap. 9.

AQUINO, Julio Groppa. A indisciplina e a escola atual. Revista da Faculdade de Educação, São Paulo, v. 24, n. 2, p. 1-11, jul./dez. 1998. Disponível em: < http://www.scielo.br/scielo.php?script=sci arttextGpid=S0102-255519980002000 11 > . Acesso em: 10 set. 2008 .

ARIÉS, Philipe. A família. In: . História social da criança e da família. Rio de Janeiro: Zahar Editores, 1978. Cap. 3.

ASSIS, Nízia de. Revendo o meu fazer sob uma perspectiva teórico-prática. In: GRINSPUN, Mirian P. S. Zippin (Org.). A prática dos orientadores educacionais. São Paulo: Cortez, 1994. p. 125-141.

BRASIL. Lei no 8069, de 13 de julho de 1990. Dispõe sobre o Estatuto da Criança e do Adolescente e dá outras providências. Diário Oficial [da] República Federativa do Brasil, Brasília, DF, 16 jul. 1990. Disponível em: <http://www.planalto.gov.br/ccivil/LEIS/L8069.htm>. Acesso em: 15 out. 2008.

BRASIL. Lei n 9394, de 20 de dezembro de 1996. Estabelece as diretrizes e bases da educação nacional. Diário Oficial [da] República Federativa do Brasil, Brasília, DF, 23 dez. 1996. Disponível em: $<$ http://www.planalto.gov.br/ccivil_03/LEIS/L9394.htm>. Acesso em: 15 out. 2008.

CHARLOT, Bernard. Da relação com o saber: elementos para uma teoria. Porto Alegre: Artes Médicas Sul, 2000.

COELHO, Lígia Martha Coimbra da Costa. Escola pública de horário integral: um tempo (fundamental) para o ensino fundamental. In: ABRAMOWICZ, Anete; MOLL, Jaqueline (Orgs.). Para além do fracasso escolar. 4. ed. Campinas, São Paulo: Papirus, 1997. Cap. 11. 
DUARTE, Sandra M. N. Moura. O emprego das mulheres e as estruturas de apoio às crianças. In: CONGRESSO PORTUGUÊS DE SOCIOLOGIA, 4., 2000, Lisboa. Actas... Lisboa: Associação Portuguesa de Sociologia, 2000. Disponível em: < http://www.aps.pt/cms/docs_prv/docs/ DPR462e040a7a15a_1.PDF>. Acesso em: 14 out. 2008.

ESTEBAN, Maria Teresa. A avaliação no cotidiano escolar. In: ESTEBAN, Maria Teresa (Org.). Avaliação: uma prática em busca de novos sentidos. 4. ed. Rio de Janeiro: DP\&A, 2003. p. 7-28.

FRANCO, Maria Laura P. Barbosa. Pressupostos epistemológicos da avaliação educacional. In: SOUZA, Clarilza Prado de (Org.). Avaliação do rendimento escolar. 13. ed. Campinas, São Paulo: Papirus, 2005. p. 13-26.

KALOUSTIAN, Sílvio Manoug (Org.). Família brasileira: a base de tudo. 3. ed. São Paulo: Cortez; Brasília, DF: Unicef, 1998.

LIBÂNEO, José Carlos. Didática. São Paulo: Cortez, 1996.

LIBÂNEO, José Carlos; OLIVEIRA, João Ferreira de; TOSCHI, Mirza Seabra. Educação escolar: políticas, estrutura e organização. 5. ed. São Paulo: Cortez, 2007.

MALAVAZI, Maria Márcia Sigrist. Os pais e a vida escolar dos filhos. 2000. 320 p. Tese (Doutorado em Educação) - Faculdade de Educação, Universidade Estadual de Campinas, 2000.

MOYSÉS, Lúcia. O desafio de saber ensinar. Campinas: Papirus, 1994.

PARO, Vitor Henrique. Administração escolar e qualidade de ensino: o que os pais ou responsáveis têm a ver com isso? In: BASTOS, João Baptista (Org.). Gestão democrática. 2. ed. Rio de Janeiro: DP \& A, 2001. p. 57-72.

. Qualidade do ensino: a contribuição dos pais. 3. reimpr. São Paulo: Xamã, 2007. . Gestão democrática da escola pública. 3. ed. São Paulo: Ática, 2008.

PATTO, Maria Helena Souza. A produção do fracasso escolar: histórias de submissão e rebeldia. São Paulo: Casa do Psicólogo, 1999.

PAULA, Flávia Anastácio de. Lições, deveres, tarefas, para casa: velhas e novas prescrições para professoras. 2000. 250 f. Dissertação (Mestrado em Educação) - Faculdade de Educação, Universidade Estadual de Campinas, Campinas, 2000. Disponível em:

$<$ http://cutter.unicamp.br/document/?code $=$ vtls000214661 \&fd =y $>$. 
POLÔNIA, Ana da Costa; DESSEN, Maria Auxiliadora. Em busca de uma compreensão das relações entre família escola. Psicologia Escolar e Educacional, Campinas, v. 9, n. 2, p. 303-312, dez. 2005.

SPÓSITO, Marília Pontes. Educação, gestão democrática e participação popular. In: BASTOS, João Baptista (Org.). Gestão democrática. 2. ed. Rio de Janeiro: DP \& A, 2001. p. 45-56.

TRIVIÑOS, Augusto Nibaldo Silva. Introdução à pesquisa em ciências sociais: a pesquisa qualitativa em educação. São Paulo: Atlas, 1995.

VENOSA, Sílvio de Salvo. Direito civil: direito da família. 5. ed. São Paulo: Atlas, 2005. v. 6.

Adriana Varani, doutora em Educação pela Universidade Estadual de Campinas (Unicamp), é professora da Universidade Federal de São Carlos (UFSCar), no campus de Sorocaba-SP.

varani@ufscar.br

Daiana Cristina Silva, pedagoga pela Pontifícia Universidade Católica de Campinas (PUC-Camp), é professora no ensino fundamental na cidade de Itapira-SP.

daiacristi@hotmail.com

Recebido em 7 de abril de 2010.

Aprovado em 16 de setembro de 2010. 